\title{
Interhemispheric interaction in the motor domain in children with cerebral palsy
}

\author{
Nadezhda V. Zaytseva ${ }^{1}$, M. Sami Walid ${ }^{2}$, Elena M. Berdichevskaia ${ }^{3}$ \\ ${ }^{1}$ Department of Physical Education, Kuban State Medical University, ${ }^{3}$ Department of Physiology, Kuban State University of Physical \\ Education, Sport and Tourism, Krasnodar, Russia, ${ }^{2}$ Georgia NeuroCenter, Medical Center of Central Georgia, Macon, GA, USA
}

\begin{abstract}
Background: The attention of pediatric specialists has been continuously attracted to the problem of cerebral palsy (CP) and the formation of behavioral and motor skills in the initial years of life in these patients. This work aimed at studying the specifics of intra- and interhemispheric connections in the motor domain in children with $\mathrm{CP}$ as well as their dynamics in the process of rehabilitation using hand/finger synkineses and and lateral profile as markers. Materials and Methods: A total of 215 children aged 4-7 years were recruited after obtaining their parents' consent, including 95 patients with the most prevalent forms of CP (spastic diplegia, hemiparetic form) who underwent complex treatment in a neuropsychological sanatorium and 120 healthy children from a kindergarten. Data were analyzed using nonparametric methods and the chi-sQuare test with the help of the statistical program SPSS v.14. Results: Changes in the scores and types of synkinesis after rehabilitation indicated that in spastic diplegia the assumed symmetric brain defects were associated with uniform restoration of interhemispheric connections and less disturbance of intrahemispheric connections. In hemiplegia, on the contrary, misbalance in intrahemispheric connections prevailed and compensation was noticed only in left-hemispheric pathology. The magnitude, type, and improvement of hand synkineses in the course of treatment depended on the lateral phenotype. Conclusion: Hand/finger synkineses in CP children change with rehabilitation. The methods used in the study can be recommended for application in the system of medico-biological and psycho-pedagogical monitoring of children with $\mathrm{CP}$.
\end{abstract}

Address for correspondence:

Dr. Nadezhda V. Zaytseva,

Kuban State Medical University,

4 Sedina Street,

Krasnodar - 350 063, Russia.

E-mail: Zacev77@yahoo.com

DOI: $10.4103 / 0028-3886.55608$
Key words: Cerebral palsy, synkinesis, functional asymmetry

\section{Introduction}

The last two decades has witnessed numerous publications addressing the characteristics of coordinated activity of brain hemispheres in the course of development of human organism (ontogenesis). ${ }^{[1-6]}$ However, the mechanisms of hemispheric interaction when performing different motor activities and the role of functional asymmetry of the brain in the early stages of ontogenesis remains inadequately investigated. ${ }^{[7,8]}$ Finding answers to this question will allow viewing from new positions the central adaptational mechanisms during the growth process of children with neurological pathology. For that, physiologists and symmetry researchers have been studying the asymmetric motor problems characteristic of children's cerebral palsy
(CP) ${ }^{[9-11]}$ a pathology that has increased in Russia after the fall of the Soviet Union to over 3 per 1,000 births. ${ }^{[12]}$ Since the basis of behavioral and motor skills form mainly in the first years of life, the analysis of particulars of interhemispheric interaction is very important in outlining a rehabilitation plan for this category of patients. ${ }^{[13-15]}$ Different methods have been reported useful in investigating patterns of functional recovery, mirror movements and interlimb coordination in children with cerebral palsy, from repetitive manual squeezing tasks (grip assessment) to video recording to transcranial magnetic stimulation and motor evoked potentials. ${ }^{[16-18]}$ Studying hand and finger synkineses (the involuntary movements that accompany intentional movements) has also been reported as a simple method in the methodological analysis of intra- and 
interhemispheric interaction in the motor sphere in normal and children with neurological pathology.$^{[19-21]}$ Synkineses are considered a secondary manifestation of intra- and interhemispheric interaction in the functional organization of the motor act. ${ }^{[7,19,22]}$ This work aimed at studying the specifics of intra- and interhemispheric connections in the motor domain in children with $\mathrm{CP}$ as well as the dynamics of synkinetic disturbances in the process of rehabilitation.

\section{Materials and Methods}

After obtaining the approval of the scientific Council of Kuban State University of Physical Education, Sport and Tourism, we recruited 215 children, aged between four and seven years, whose parents gave permission to include in the study. Among these children, 95 patients had the most common forms of $\mathrm{CP}$ of mild-to-moderate severity: Spastic diplegia $(\mathrm{n}=40)$, right hemiparesis/ plegia $(n=30)$ and left hemiparesis/plegia $(n=25)$, who passed three and a half months of comprehensive treatment at Krasnodar Regional Neuropsychological Sanatorium «Solnitshko», and 120 healthy children from Kindergarten № 101, an ordinary nursery school in Krasnodar. The study took place in 2003 and consisted of two evaluations of the children: in the first 2-3 weeks of arrival in the sanatorium and two weeks before leaving the sanatorium.

In Russia, the widely used classification of $\mathrm{CP}$ forms suggested by Semenova (1999) takes into consideration the maturity of the motor, intellectual, psychological, emotional and speech aspects of the child. ${ }^{[23]}$ According to this classification, the following forms can be distinguished: Spastic forms $(60 \%),{ }^{[24]}$ including dual (spastic) hemiplegia, in which the functions of upper and lower extremities are disturbed to equal degrees or the upper extremities suffer mainly from markedly tonic reflexes and muscle rigidity, and spastic diplegia (little syndrome) in which the lower extremities are most affected. The hyperkinetic form is characterized by the presence of involuntary uncontrolled movements in the form of chorea (quick movements vaguely comparable to dancing) or athetosis (slow writhing movements) or cheaoathetosis (combination of both). The atonic-astatic form is distinguished by wide-range movements of the extremities with problems in balance and possible hand tremor. In the hemiparetic/ plegic form $(15 \%),{ }^{[25]}$ there is severe disturbance in the basic functions of one upper and one lower extremity on the same side. In all the abovementioned forms of $\mathrm{CP}$ three degrees of severity can be noticed: Mild when the physical defect allows ambulation and self-care but causes clumsiness of movements, moderate when patients need some help from surrounding people in walking and self-service, and a severe form when children can not walk independently. In Russia, physicians dealing with
$\mathrm{CP}$ patients often combine the first and second degrees of severity together and write the diagnosis as " $\mathrm{CP}$ of mildto-moderate severity." This corresponds to levels 1-3 of the Gross Motor Function Classification System for CP. ${ }^{[26]}$

The complex treatment of children with CP in the neuropsychological sanatorium was individualized and dependent on age, form and severity of the disease. It included medical treatment, orthopedic regime, gradual splinting, acupuncture, physiotherapy, massage (classical therapeutic, segmental, punctual, sedative and tonic), logopedic and physical education exercises. Special attention was paid to physical exercises in the reflex-loading apparatus Gravistat (Cosmic Costume) designed by the constructors of the scientific research center Ogonek (www.ogonek.org) in Moscow for the rehabilitation of children with CP. Exercises using hand finger synkineses were conducted individually under the supervision of a qualified instructor. The structure of the costume allows the calculation and distribution of load which can be directed along the longitudinal axis of the body. It was specifically designed for the application of the dynamic propioceptive correction method described later in the works of Semenova (1999) in which steady suppression of tonic reflexes and restoration of adjusting reflexes take place during exercises with functional correction of the pathologic posture. ${ }^{[23]}$

For the assessment of the functional mechanisms of intra-and interhemispheric interaction in the organization of motor activity we used the hand/finger synkinesis probe [Figure 1]. ${ }^{[19-22,27]}$ Results were assessed on a scale from 1 to 5 , as suggested by Zeigarnik (1987). ${ }^{[27]}$ Thus, the more optimal interhemispheric connections worked the less synkineses were manifested, and the higher the score was. Bilateral synkineses of fingers, performed separately or simultaneously in both hands by different fingers (asynchronous, crossed) were

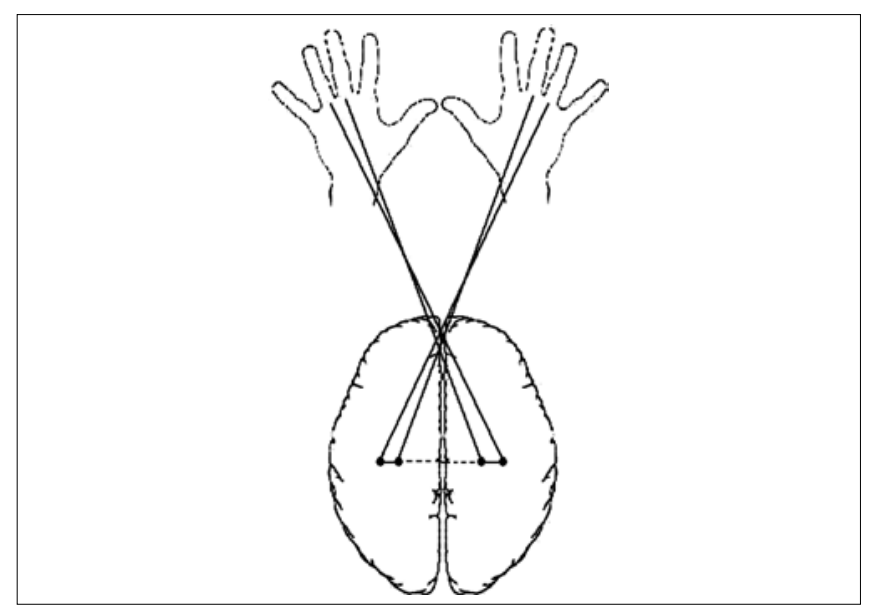

Figure 1: Sketch of inter- and intrahemispheric connections and hand/ finger synkineses 

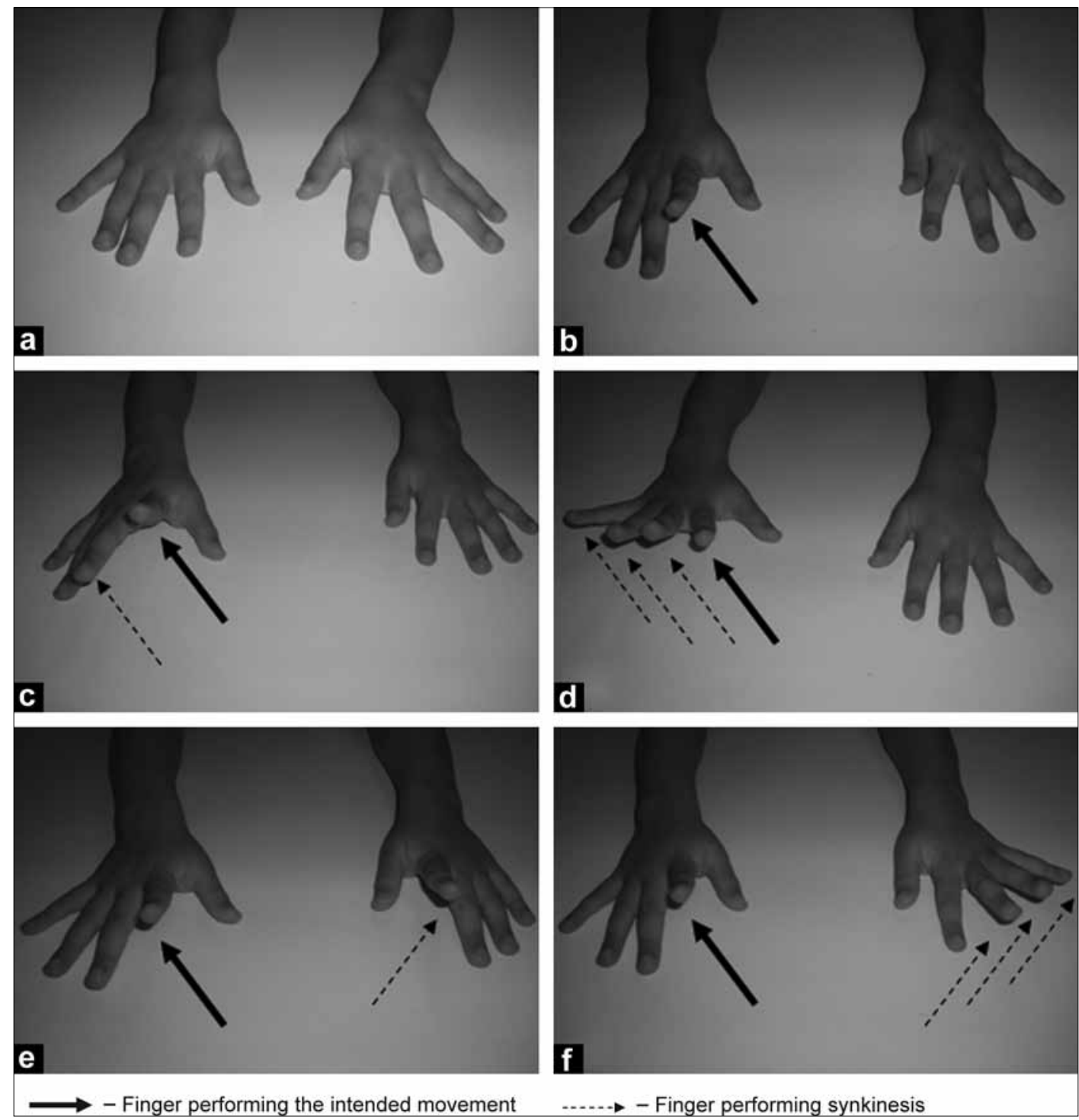

Figure 2: Hand/finger synkinesis test (a) Initial level; (b) No synkinesis; (c) Unilateral, occasional synkineses; (d) Unilateral, consistent synkineses; (e) Bimanual, synchronous, crossed synkineses; (f) Bimanual, asynchronous, crossed synkineses

scored as one; synchronous, crossed synkineses as two; unilateral, consistent synkineses as three; unilateral occasional synkineses as four; and absence of synkinesis as five [Figure 2]. Crossed synkineses reflected the function of interhemispheric connections, while the remaining variants intrahemispheric connections. ${ }^{[7]}$

The Individual Profile of Asymmetry (IPA), or the Lateral Phenotype, was determined using the method of Bragina and Dobrokhotova (1988), which we modified to fit the specifics of perception in preschool children. ${ }^{[28]}$ It consists of 25 tests that check preferences in vision, hearing and motor activity of the upper and lower extremities. The asymmetry coefficient is calculated using the same author's formula: CoefAsym $=100 *(\mathrm{TR}-\mathrm{TL} / \mathrm{TR}+\mathrm{TL}+\mathrm{TO})$, where CoefAsym is the Coefficient of Asymmetry, TR is the number of tests of a paired organ with right dominance; $\mathrm{TL}$ is the number of tests with left dominance; and TO is the number of tests with no dominance. When CoefAsym is $>+15 \%$ the right dominates, when CoefAsym is $<-15 \%$ the left dominates, and when CoefAsym is between $+15 \%$ and $-15 \%$ there is symmetry. In every group, depending on the IPA of upper extremities, lower extremities, vision and hearing, we marked out «absolutely» rightist, "partially» and «absolutely» leftist subgroups. According to Bragina and Dobrokhotova, «partially» leftist people are those with 1-3 left sensori-motor signs; thus, there are no partially «rightist» individuals.

Concisely, the paper aimed at studying the following points:

1. The average synkinesis scores and types of synkineses in normal and $\mathrm{CP}$ children and changes from baseline due to rehabilitation; 
2. Changes from baseline in the average score and types of synkineses in normal and $\mathrm{CP}$ children with different lateral phenotypes due to rehabilitation.

Experimental data were processed using non-parametric methods (the Wilcoxon-Mann-Whitney test) and the chi-square test for categorical variables with the help of the statistical program SPSS v.14. The arithmetic average $(\mathrm{m})$, standard deviation $( \pm \sigma)$, and significance value $(P)$ were calculated.

\section{Results and Discussion}

Before rehabilitation, children with spastic diplegia had the lowest average score of synkineses, 1.3 vs. 3.6 for healthy children. In the hemiparetic form, it was significantly higher than in spastic diplegia (0.05), 2.0 and 2.2 for left or right brain hemisphere pathology (corresponding to right and left hemiparesis), respectively [Figure 3].

After treatment, the amount of synkineses decreased in spastic diplegia by $38 \%$ and in right hemiparesis by $35 \%$ $(<0.05)$. This drop reflected an improvement in intra- and interhemispheric collaboration in the control of motor activity. There were no positive changes in patients with left hemiparesis [Figure 3].

Detailed analysis of types of synkinesis showed particularities in patients with different forms of CP. Before the beginning of treatment, synkineses were noted in $96 \%$ of patients with spastic diplegia. Most commonly, bimanual synkineses were found in $83 \%$ of patients, including synkineses which manifested themselves separately in each hand and so reflected defects in intrahemispheric connections in each hemisphere. These were encountered in $30 \%$ of cases. Asynchronous, crossed synkineses, which manifested themselves simultaneously in two hands and reflected misbalance in interhemispheric connections, were noted in 53\% of cases. Bimanual synkineses indicated the child's inability to selectively and arbitrarily control every finger apart and the right and left hands individually. Synchronous, crossed synkineses were absent. In a small number of children, one-sided consistent $(9 \%)$ and occasional (4\%) synkineses were noted in the non-dominant hand. Absence of synkineses was noticed in $4 \%$ of patients only [Figure 4].

In children with the hemiparetic form of $\mathrm{CP}$, synkineses were always present except for synchronous, crossed ones. In right hemiparesis, they were more often bimanual (61\%) synkineses and practically in all fingers of the «ill» extremity, which pointed to

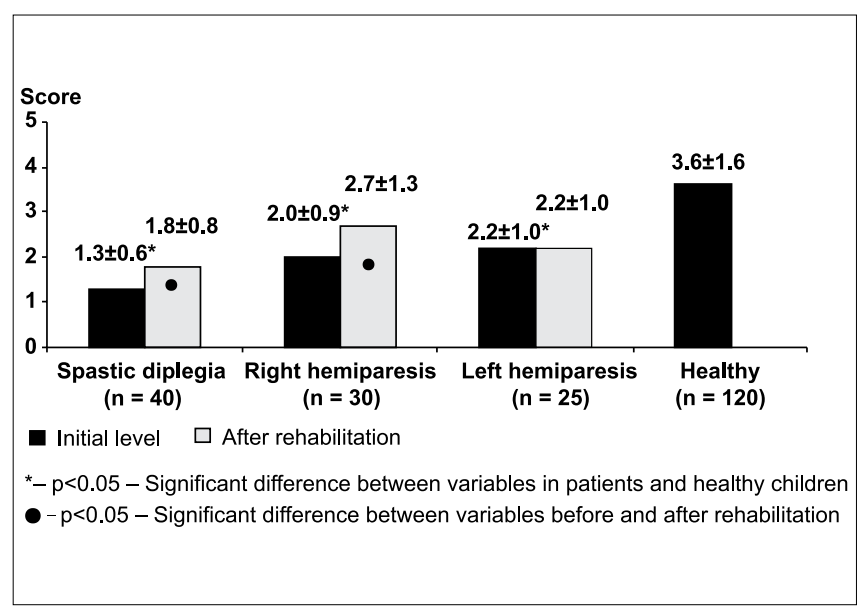

Figure 3: Synkinesis scores $(m \pm \sigma)$ in $\mathrm{CP}$ patients and in healthy children before and after rehabilitation

significant impairment of intra- and interhemispheric coordination. Bimanual, separate synkineses made up $23 \%$; asynchronous, crossed $38 \%$; one-sided, consistent $26 \%$; and occasional $13 \%$ of all synkineses. In left hemiparesis, bimanual, separate synkineses were manifested in the «ill» extremity in $20 \%$; asynchronous, crossed in $34 \%$; one-sided, consistent and occasional in $15 \%$ and $31 \%$ of cases, respectively [Figure 4 ].

Thus, in patients with spastic diplegia, problems with interhemispheric connection prevailed over the disturbance in the intrahemispheric relays, supposedly characteristic of hemiparetic forms. In hemiparesis, disturbances were more obvious on the «ill» side, especially in right hemiparesis (pathology of the left hemisphere).

In healthy children of preschool age, synkineses were manifested in $60 \%$ of cases, mainly in the form of one-sided, occasional synkineses [Figure 4].

Changes in types of synkinesis after complex treatment in the rehabilitation center were dependent on the forms of CP [Figure 4]. Thus, in spastic diplegia, the number of bimanual synkineses went down noticeably $(20 \%,<0.05)$, including those performed separately by both hands (10\%) and asynchronous, crossed synkineses $(10 \%)$. They transformed to synchronous, crossed and one-sided, consistent synkineses. The number of occasional synkineses increased. The number of children who became synkineses-free went up to $8 \%$.

In right hemiparesis, the number of bimanual synkineses decreased by $31 \%$ - synkineses performed separately by both hands decreased by $7 \%$ and asynchronous, crossed ones by $24 \%$. Synchronous, crossed synkineses appeared in $9 \%$ of cases. The amount of one-sided occasional synkineses grew up by $21 \%$ at the expense of bimanual and one-sided, consistent ones which were diminished. There appeared 


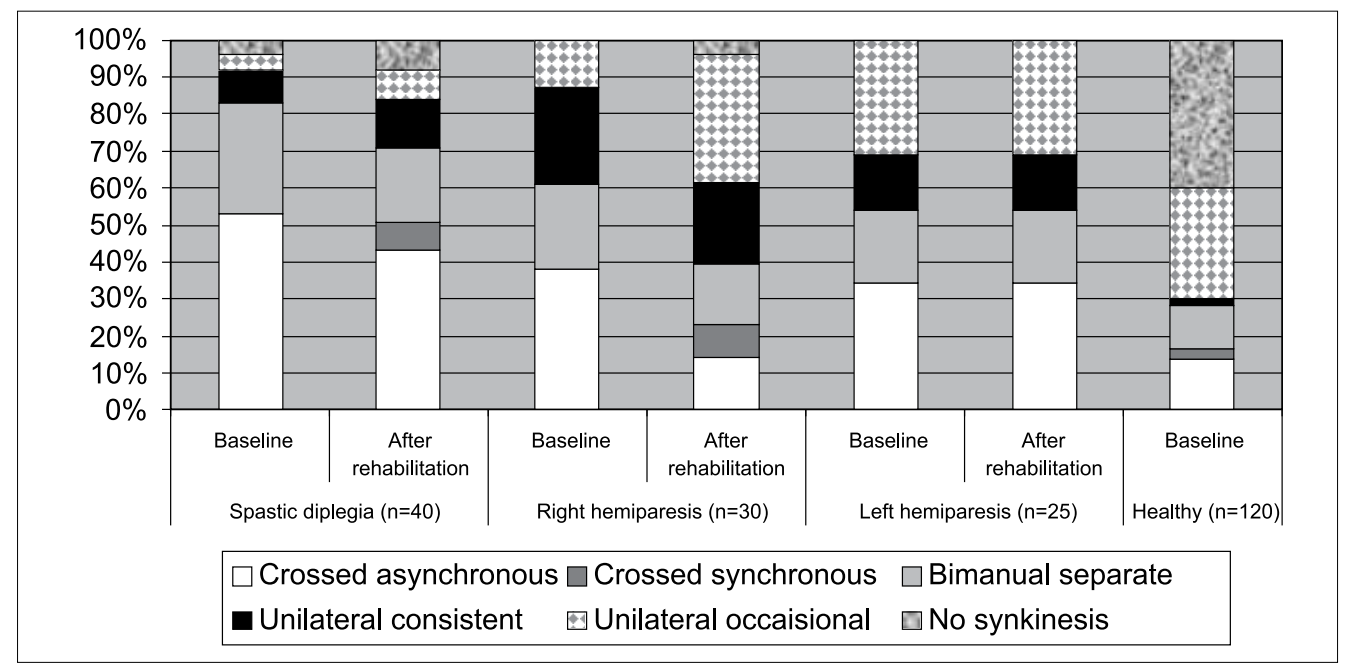

Figure 4: Synkinesis types in children with CP before and after rehabilitation and in healthy children

cases without synkineses (4\%). In left hemiparesis, there was no change in the character of synkineses.

Children with spastic diplegia, in the course of rehabilitation, were noticed to have a tendency for uniform restoration of the impaired intra- and interhemispheric connections. In right hemiparesis, compensatory processes involved, to a wider degree, the restoration of interhemispheric connections. In total, the quantitative and qualitative analysis of synkineses objectively reflected the optimization of central communications responsible for purposeful and arbitrary control of hand and finger movements.

Depending on the four sensori-motor organs (hand, foot, eye and ear) and the IPA, three subgroups can be distinguished among healthy children: «absolute» rightists, "partial» leftists and «absolute» leftists. In children with $\mathrm{CP}$, there are fewer subgroups. Thus, among patients with spastic diplegia and left hemiparesis, «absolute» rightists and "partial» leftists are encountered, but «absolute» leftists are absent. With left hemiparesis (pathology of right hemisphere a natural leftist acquires forced dominance of the right side of the body. In right hemiparesis, «absolute» and «partial» leftists are discernible and no «absolute» rightists can be identified due to the weakness of the right side of the body.

Our data show that the degree of manifestation of synkineses in patients with CP before the beginning of treatment and in healthy children was not dependent on IPA [Table 1]. However, in patient with CP a relationship was uncovered between the lateral phenotype and improvement under the rehabilitation program with regard to synkinesis. Thus, «partially» leftist children with spastic diplegia were noticed to have bigger difference (by $15 \%$ ) in the average score of synkineses and the restoration
Table 1: Dynamics of synkines scores in cerebral palsy patients and healthy children per lateral phenotype $(m \pm \sigma)$

\begin{tabular}{llcc}
\hline Form of CP & $\begin{array}{l}\text { Lateral } \\
\text { phenotype }\end{array}$ & \multicolumn{2}{c}{ Score for fingers' synkineses } \\
\cline { 2 - 4 } & Initial levels & After treatment \\
\hline $\begin{array}{l}\text { Spastic } \\
\text { diplegia } \\
(n=40)\end{array}$ & $\begin{array}{l}\text { «Absolute» rightist } \\
(n=14)\end{array}$ & $1.9 \pm 0.7$ & $2.3 \pm 1.1^{*}$ \\
«Partial» leftist & $1.1 \pm 0.5$ & $1.5 \pm 0.7^{*}$ \\
$\begin{array}{l}\text { Right } \\
\text { hemiparesis } \\
(n=30)\end{array}$ & $\begin{array}{l}\text { «Absolute» leftist } \\
(n=12)\end{array}$ & $2.2 \pm 0.9$ & $2.9 \pm 1.3^{*}$ \\
«Partial» leftist & $1.6 \pm 0.7$ & $2.5 \pm 1.2^{*}$ \\
$\begin{array}{l}\text { Left } \\
\text { hemiparesis } \\
(n=25)\end{array}$ & $\begin{array}{l}\text { «Absolute» rightist } \\
(n=13)\end{array}$ & $1.9 \pm 0.9$ & $1.7 \pm 0.8$ \\
«Partial» leftist & $2.4 \pm 1.1$ & $2.6 \pm 1.2$ \\
$\begin{array}{l}\text { Healthy } \\
\text { children } \\
(n=120)\end{array}$ & $\begin{array}{l}\text { «Absolute» rightist } \\
(n=20)\end{array}$ & $3.1 \pm 1.1$ & - \\
& $\begin{array}{l}\text { «Partial» leftist } \\
(n=96)\end{array}$ & $3.5 \pm 1.3$ & - \\
& $\begin{array}{l}\text { «Absolute» leftist } \\
(n=4)\end{array}$ & $3.8 \pm 1.9$ & - \\
\hline "P<0.05, - Significant difference between variables before and after treatment
\end{tabular}

of their impaired inter-central communications than in «absolute» rightists (<0.05). Similarly, «partial» leftist children with right hemiparesis had better restoration of impaired central communications than «absolute» leftists by $24 \%(<0.05)$. In left hemiparesis, there were no positive changes in groups with different IPAs.

Synkinesis character/type before and after treatment was dependent on IPA in CP patients but not in healthy children [Figure 5,IV].

Before the beginning of treatment, synkineses were $14 \%$ less in «absolute» rightist children with spastic diplegia than in "partial» leftist partners. In cases of right hemiparesis, "partial» leftist children had 22\% more bimanual synkineses, performed simultaneously 


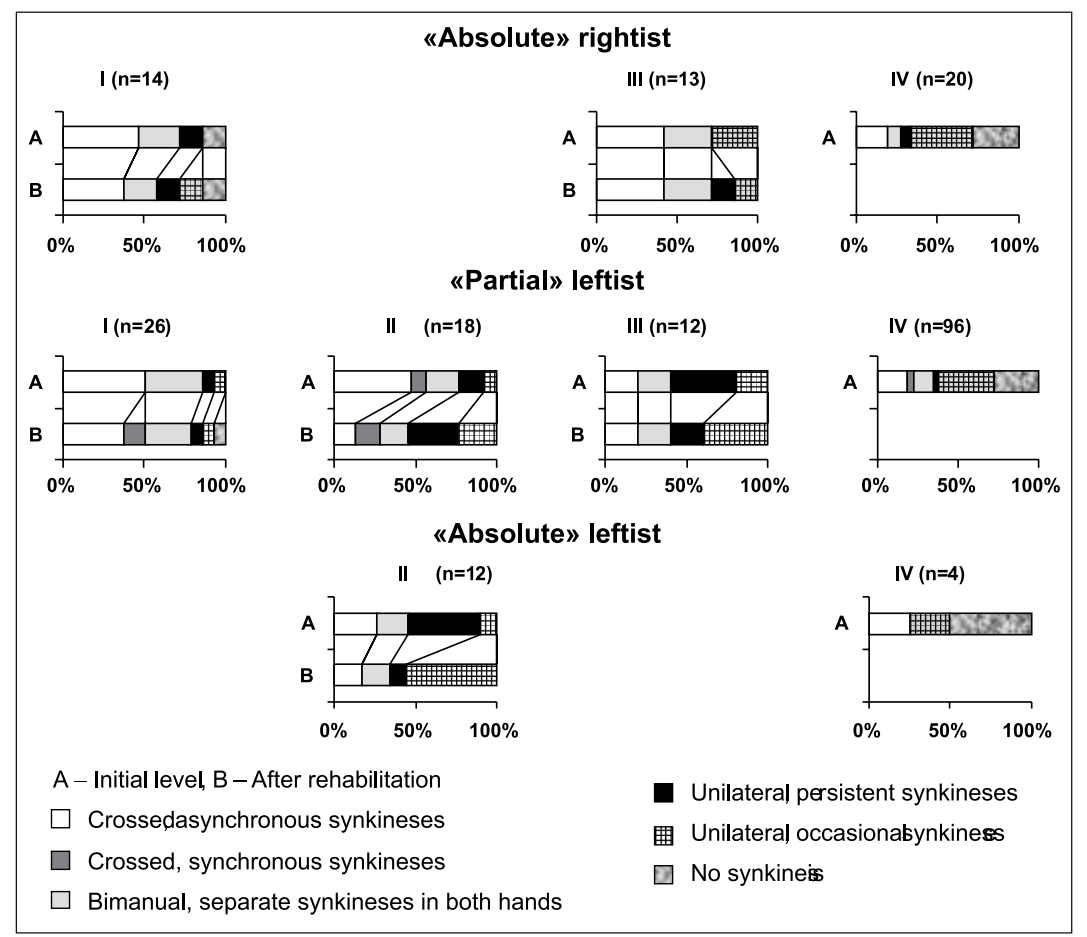

Figure 5: Synkinesis types in patients with (I) spastic diplegia, (II) right or (III) left hemiparesis and in (IV) healthy children depending on lateral phenotype

with both hands, and 30\% less one-sided, consistent synkineses than their «absolute» partners. This indicated more hemispheric generalization and less misbalance in intrahemispheric connections in «partial» leftist children. In left hemiparesis, «partial» leftist children had more optimal intra- and interhemispheric connections than «absolute» rightist children owing to the predominance of one-sided synkineses (by 31\%) and the less quantity of asynchronous, crossed synkineses (by 22\%).

Positive changes in synkinesis character in the process of rehabilitation in patients with $\mathrm{CP}$ depended on the lateral phenotype [Figure 5,I-III]. In «absolute» rightist children with spastic diplegia, hemispheric connections became better at the expense of a decrease in the quantity of bimanual, asynchronous, crossed synkineses (by $17 \%$ ) and the appearance of one-sided, occasional synkineses (in $14 \%$ of cases). In «partial» leftist children, more types of synkinesis persisted than in their «absolute» leftist partners.

In «partial» leftist children with right hemiparesis, there was a drop in the quantity of bimanual synkineses, performed simultaneously by both hands (by 35\%) and a rise in the number of synchronous, crossed synkineses (by 7\%) and one-sided, consistent and occasional synkineses (by 16\% and 15\%). In «absolute» leftist children, the amount of bimanual, asynchronous, crossed and one-sided, consistent synkineses dropped by $7 \%$ and $35 \%$, respectively; synchronous, crossed synkineses disappeared and the number of one-sided, occasional synkineses rose by $46 \%$. In left hemiparesis, there were no IPA-dependent changes in the character of synkinesis in the course of rehabilitation.

The functional integrity of brain hemispheres ensures the balance of hemispheric connections; however, the median localization of the pathological nidus in patients with spastic diplegia significantly impairs the functional integration of both hemispheres. It was characteristic for patients with $\mathrm{CP}$ to have a significantly bigger amount of diverse synkineses in comparison with normal peers and, therefore, a lesser score. The preservation of interhemispheric connections and the specifics of restoration of hemispheric interaction in the process of rehabilitation appeared to be dependent on CP form. It was remarkable that children 4-7 years of age with $\mathrm{CP}$ had notable impairment of intra- and interhemispheric interaction and consequently of selective, subjective, and separate control of each finger in comparison with healthy peers. Complex rehabilitation of these ill children helps partially restore their intra- and interhemispheric connections. In spastic diplegia, symmetric defects in the interhemispheric commissures and around brain ventricles condition the uniform restoration of interhemispheric communications and the less disturbed intrahemispheric connections. ${ }^{[29,30]}$ On the contrary, in hemiparesis, ${ }^{[25,31,32]}$ with the lesion mainly cortical in one hemisphere, misbalance in intrahemispheric connections predominates and compensation is noted only in left-hemispheric pathology. In our study, the magnitude, character, and positive changes in synkineses in the course of treatment depended on the lateral 
phenotype of the ill child. Moreover, it was characteristic for every form of CP to impact IPA and the dynamics of rehabilitation. In «absolute» rightist children with spastic diplegia the number of synkineses was less before the beginning of treatment; therefore, the end result of treatment concerning the positive dynamics of synkineses reflecting interhemispheric connections was better than in "partial» leftists despite the smaller ranges of restoration of impaired interhemispheric connections. In «absolute» leftists with right hemiparesis, a better picture of the character of synkineses before the beginning of treatment and their positive dynamics in the process of rehabilitation was noted, in comparison with «partial» leftists, despite the less scopes of restoration of impaired intercentral relationships.

On the basis of the results above, a conclusion can be made that hand and finger synkinesis tests can be added to the grip assessment test when evaluating the disability of CP-affected hands during their functional recovery. Methods for elucidation of pathologic synkineses, including those described in this paper for investigating motor function in children with $\mathrm{CP}$, can also be recommended for application in the system of medico-biological and psycho-pedagogical monitoring. They represent objective criteria for evaluating tempos of maturation of the central nervous system in healthy children and adaptive-compensatory transformations in the presence of neurological pathology. In the presence of motor and, especially, crossed synkineses, we need to pay attention to the value of performing additional therapeutic measures aiming at improving manual coordination and the activation of recuperation of functional capacities in the course of rehabilitation of patients with $\mathrm{CP}$.

\section{References}

1. Davidson RJ, Hugdahl K. Brain asymmetry. Cambridge (MA): MIT Press; 1995.

2. Egorov AU. Substitution of paradigms in teachings about functional asymmetry of the brain, from the conception of specialization of hemispheres to the conception of interhemispheric interaction. In: Abstracts of the XXX All-Russian convention on the problems of higher neurological functions. St. Petersburg; 2000. p. 577-80.

3. Annett M. Handedness and brain asymmetry: The right shift theory medical. Hove (UK): Psychology Press; 2002.

4. Hugdahl K, Davidson RJ. The asymmetrical brain. Cambridge (MA): MIT Press; 2003.

5. Kuraev GA, Soboleva LG, Sorokoletova LG. The formation of interhemispheric functional asymmetry of the brain in the process of learning. In: Bogolepova NN, Fokin VF, editors. Functional interhemispheric asymmetry. Chrestomathy. Moscow: Scientific World; 2004. p. 125-162.

6. Boles DB, Barth JM, Merrill EC. Asymmetry and performance: Toward a neurodevelopmental theory. Brain Cogn 2008;66:124-39.

7. Zaytseva NV, Berdichevskaia EM. Synkinesis and hemispheric interaction in cerebral palsy. Journal of the Russian American Medical Association 2008;5:25.

8. Stroganova TA, Pushina NP, Orekhova EV, Posikera IN, Tsetlin MM. Functional brain asymmetry and individual differences in hand preference in early ontogenesis. Fiziol Cheloveka 2004;30:20-30.

9. Erkin G, Delialioglu SU, Ozel S, Culha C, Sirzai H. Risk factors and clinical profiles in Turkish children with cerebral palsy: Analysis of 625 cases. Int J Rehabil Res 2008;31:89-91.

10. O'Shea M. Cerebral palsy. Semin Perinatol 2008;32:35-41.

11. Sanger TD. Is Cerebral Palsy a Wastebasket Diagnosis? J Child Neurol 2008;23:726-8

12. Bronnikov VA, Abramova NA. Higher cortical functions in children with spastic forms of cerebral palsy. Zh Nevrol Psikhiatr Im S S Korsakova 2004;104:9-15.

13. Masur H, Papke K, Althoff S, Oberwittel C. Scales and scores in neurology: Quantification of neurological deficits in research and practice. Stuttgart (NY): Thieme; 2004.

14. Arnould C, Penta M, Thonnard JL. Hand impairments and their relationship with manual ability in children with cerebral palsy. J Rehabil Med 2007;39:708-14.

15. Blank R, Kries R, Hesse S, Voss H. Conductive education for children with cerebral palsy: Effects on hand motor functions relevant to activities of daily living. Arch Phys Med Rehabil 2008;89:251-9.

16. Kuhtz-Buschbeck JP, Sundholm LK, Eliasson AC, Forssberg H. Quantitative assessment of mirror movements in children and adolescents with hemiplegic cerebral palsy. Dev Med Child Neurol 2000;42:728-36.

17. Fedrizzi E, Pagliano E, Andreucci E, Oleari G. Hand function in children with hemiplegic cerebral palsy: Prospective follow-up and functional outcome in adolescence. Dev Med Child Neurol 2003;45(2):85-91.

18. Nezu A, Kimura S, Takeshita S, Tanaka M. Functional recovery in hemiplegic cerebral palsy: Ipsilateral electromyographic responses to focal transcranial magnetic stimulation. Brain Dev 1999;21:162-5.

19. Shanina GE. Exercises of the special kinesiological complex for the restoration of interhemispheric interaction in children and teenagers. Teaching manual. Moscow: Moscow State University Publications; 1999

20. Sirotuk AL. Teaching children in view of psychophysiology. Moscow: Sphera; 2000.

21. Park IS, Song IU, Lee SB, Lee KS, Kim HT, Kim JS. Mirror movements and involuntary homolateral limb synkinesis in a patient with probable Creutzfeldt-Jakob disease. Clin Neurol Neurosurg 2009; 111(4):380-3.

22. Khomskaia ED, Privalova NN, Enikolopova EV, Efimova IV, Budika EB, Stepanova OB. Methods of assessment of interhemispheric asymmetry and interhemispheric interaction. Moscow: Moscow State University Publications; 1995.

23. Semonova KA. Recuperative treatment of patients with residual stage of cerebral palsy. Moscow: Antidor; 1999.

24. Shabalov VA, Dekopov AV, Troshina EM Preliminary results of treatment for spastic forms of infantile cerebral paralysis by chronic epidural neurostimulation of lumbar enlargement. Zh Vopr Neirokhir Im N N Burdenko 2006;3:10-3.

25. Steenbergen B, Charles J, Gordon AM. Fingertip force control during bimanual object lifting in hemiplegic cerebral palsy. Exp Brain Res 2008;186:191-201.

26. Palisano R, Rosenbaum P, Walter S, Russell D, Wood E, Galuppi B. Development and reliability of a system to classify gross motor function in children with cerebral palsy. Dev Med Child Neurol 1997;39:214-23.

27. Zeigarnik BV, Nikolaeva VV, Lebedinski VV. Pathopsychology. Moscow: Pedagogica; 1987.

28. Bragina NN, Dobrokhotova TA. Functional asymmetry of the human being. Moscow: Medicine; 1988.

29. Miller F. Cerebral palsy. Berlin: Springer; 2005.

30. Vry J, Linder-Lucht M, Berweck S, Bonati U, Hodapp M, Uhl M, Altered cortical inhibitory function in children with spastic diplegia: A TMS study. Exp Brain Res 2008;186:611-8.

31. Sheinkman OG. Brain function peculiarities in premature babies and infants with perinatal encephalopathy and cerebral palsy. Zh Nevrol Psikhiatr Im S S Korsakova 2003;103:37-42.

32. Fenichel G. Clinical pediatric neurology - A signs and symptoms approach. 5ed. Philadelphia (PA): Saunders; 2005.

Accepted on 02-07-2009

Source of Support: Nil, Conflict of Interest: None declared. 